\title{
TRM-STRENGTHENED TIMBREL CROSS VAULTS SUBJECTED TO VERTICAL SETTLEMENTS
}

\author{
PEDRO A. CALDERÓN, ELISA BERTOLESI, MANUEL BUITRAGO, \\ JUAN J. MORAGUES AND JOSÉ M. ADAM*
}

\author{
ICITECH, Universitat Politècnica de València, Camino de Vera s/n, 46022 Valencia, Spain \\ e-mail: pcaldero@upv.es (P.A. Calderón), elber4@upv.es (E. Bertolesi), \\ mabuimo1@upv.es (M. Buitrago),jmorague@upv.es (J.J. Moragues), joadmar@upv.es (J.M. Adam) \\ (*corresponding author)
}

Keywords: Textile Reinforced Mortar (TRM), Timbrel Masonry Cross Vaults, SettlementInduced Damages, Masonry Strengthening.

\begin{abstract}
Two full-scale timbrel cross vaults subjected to vertical settlements in one of their supports were tested at the ICITECH laboratories of the Universitat Politècnica de València. In one of the vaults a support was moved downwards, while the other was subjected to upward-downward displacements in one support. Both tests are described and analysed in detail in Torres et al. [1,2]. Both vaults presented certain levels of post-test damage in the form of cracks and significant displacements. In order to analyse the effectiveness of the reinforcement of previously damaged vaults, both were strengthened with TRM and subjected to further testing in which vertical settlements were applied to one support. The TRM strengthening comprised an extrados layer composed of a 25x25 $\mathrm{mm}$ glass grid embedded into two approximately $5 \mathrm{~mm}$ thick layers of cementitious matrix. The TRM strengthening was able to withstand higher peak loads and prevent the formation of cracks along the extrados surface of the structure, while as expected, ductility increased. A $3 D$ macro-modelling FE strategy on Abaqus commercial software was also adopted to study the behaviour of the vaults during the tests.
\end{abstract}

\section{INTRODUCTION}

Most historical constructions are made of masonry [1]. During the centuries and depending from the local availability of the row materials, masonry has been constructed using different kind of blocks and type of mortars. As expected, its variety makes assessing a masonry building's safety particularly challenging. In addition, although most of the masonry constructions being part of the architectural heritage have been constructed following rules of thumb, they are currently subjected to different types of loads, for example: overloading, dynamic actions, settlement, in-plane and out-of-plane deformations [1]-[5]. In particular, the damage suffered by many historical churches and buildings after the recent Italian earthquakes [2] has shown that masonry vaulted structures are particularly vulnerable to supports distortion. Differential settlements in the supports may result in deformations, cracking, and cause changes in their geometry, twist and vertical alignment [2][4][5]. 
Evaluating the consequences associated with foundation or support movements and proposing innovative and compatible retrofitting solutions, are two of the main questions that have attracted the attention of the architects and engineers who have to preserve historical and other types of masonry constructions.

To this scope, cementitious based strengthening materials have attracted the attention of the scientific community as an alternative to Fibre Reinforced Polymer (FRP) composites for repairing historical masonry structures. Similar to FRPs, cement-based materials are lightweight, easy to apply and represent an affordable solution because of their low cost, good applicability to irregular and damp surfaces, resistance to high temperatures, good breathability, low invasiveness [6].

The mechanical properties of the substrates where TRM strengthening materials are applied, play a crucial role, since cement-based composites are often employed to reinforce weak masonries [7]. Various studies have been conducted to identify TRM's mechanical properties [8][9]. Other studies assessed the effectiveness of TRM composites applied to isolated structural elements [10][11]. Pioneering works on simple and biaxial bending TRM reinforced panels were analysed in [12][13], whereas several studies assessed the behaviour of TRM on curved weak masonry supports, including [14].

Due to their prohibitive cost, few studies have analysed the performance of TRM on fullscale structures. [15] studied the dynamic performance of a one-story masonry building tested on a vibrating table and repaired by cement-based materials. Vaults have been found to be particularly vulnerable [1][2] due to their remarkable interaction with their context, so that large differences in late the supports that have to

As no experimental s

scale cross vaulted stru

experimental campaign on full-scale masonry tir
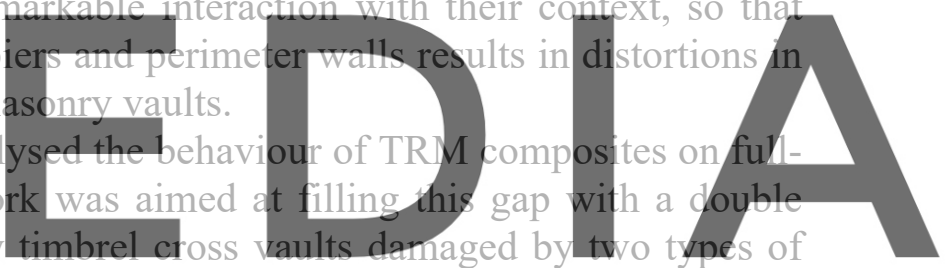

soil settlement and repaired with TRM materials.

Register for free at https//www.scipedia.com to download the version without the watermark 2 EXPERIMENTAL INVESTIGATION \& LOADING PROTOCOL

The experimental campaign investigated the behavior of two masoniry timbrel vaults reinforced with Textile Reinforced Mortar (TRM) composites when subjected to either monotonic and cyclic vertical settlements. To this scope, two masonry vaults were built at the ICITECH laboratories of the Universitat Politecnica de Valencia (Valencia, Spain). The vaults were pre-damaged in a preliminary step by applying two types of vertical movements to one of the supports [16][17].

The $4 \times 4 \mathrm{~m} 2$ square plan vaults with $1.8 \mathrm{~m}$ high lateral arches were built with 230x110x26 $\mathrm{mm} 3$ clay tiles and approximately $10 \mathrm{~mm}$ thick mortar joints. Four cubic concrete supports, S1, S2, S3 and S4, were built on steel bases. The arches were composed of four layers of clay tiles with cement mortar, plaster paste and lime mortar joints. Two vertical support distortions were applied to the damaged masonry cross vaults, i.e. a monotonic downward settlement up to $80 \mathrm{~mm}$ and an up and down cyclical displacement. Both settlements were imposed on the deformed vaults with a residual $40 \mathrm{~mm}$ downward displacement due to the need to realistically reproduce and analyze in lab conditions the repairs of the damaged masonry structures. Both excitations were imposed statically to support S1 (see Figure 1) by means of 
two manually synchronized mechanical jacks placed below the steel base. The remaining supports were constrained as follows: support S3 was fixed to the reaction floor. S2 and S4 were only allowed to slide horizontally.
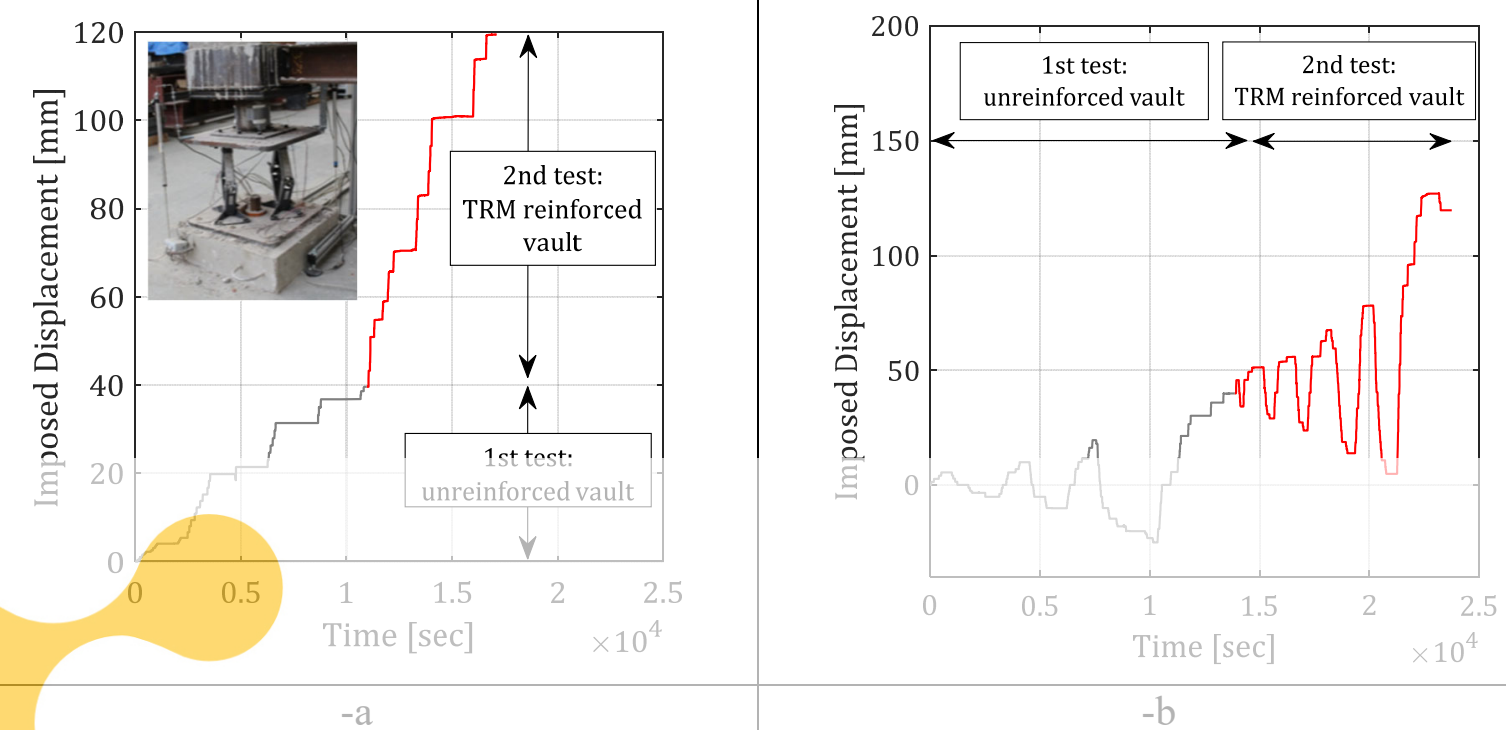

Figure 1: Comparison of displacement protocols applied to the as-built and TRM-reinforced
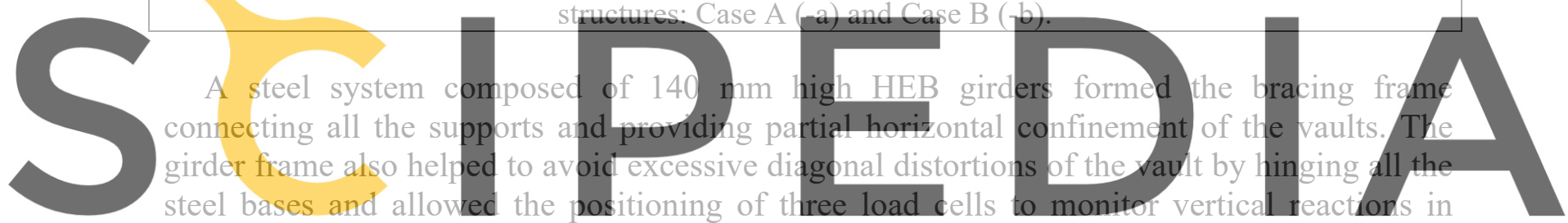

supports S1, S2 and S4.

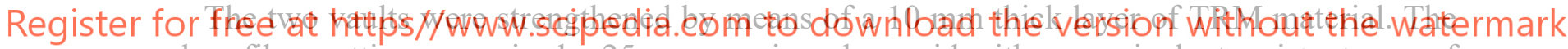
glass fiber netting comprised a $25 \mathrm{~mm}$ spacing glass grid with an equivalent resistant area of $35.27 \mathrm{~mm} 2 / \mathrm{m}$, ultimate tensile strength $45 \mathrm{kN} / \mathrm{m}$ and elastic modulus $72 \mathrm{GPa}$. The strengthening technique comprised three phases: (i) injection and masonry repointing, (ii) application of a $5 \mathrm{~mm}$ thick layer of cement mortar, (iii) placing the fiber glass fabric and (iv) finishing off with the last $5 \mathrm{~mm}$ thick mortar layer. After the injection phase, the vault extrados only was reinforced by $500 \mathrm{~mm}$ wide radially placed glass TRM strips. Glass strips were not anchored to the concrete supports, nor were spike anchors or connecting devices used.

\section{EXPERIMENTAL RESULTS: MONOTONIC SETTLEMENT}

\subsection{Experimental Results}

Figure 2-a depicts the reaction force-displacement curves obtained experimentally in supports S1, S2 and S4. As can be seen in Figure 2-a, the vault' behavior can be divided into three phases: (i) the initial elastic response was obtained up to $10 \mathrm{~mm}$, (ii) from $10 \mathrm{~mm}$ to 30 $\mathrm{mm}$ behavior was non-linear until the peak value (Rp), and (iii) in the third phase it became less pronounced with lower reaction forces up to failure at $80 \mathrm{~mm}$. The TRM had a twofold 
effect: (i) it helped to extend the elastic phase, which doubled from $5 \mathrm{~mm}$ to $10 \mathrm{~mm}$ and (ii) considerably increased the displacement capacity at failure, which doubled from 40 to $80 \mathrm{~mm}$. Apart from a few differences, the initial reactions of the TRM-reinforced vault are similar to those monitored at the end of the unreinforced vault test. Considering the as-built structure, there are negligible differences between the three reaction values in all the monitored supports, confirming an approximately equal re-distribution of the vault's weight. Conversely, the second test was performed starting from the deformed vault configuration obtained at the end of the first test and then applying the monotonic settlement. As expected, since the test started with a downward residual displacement of $40 \mathrm{~mm}$ in support S1, the equal distribution of the reaction forces in the as-built structure were altered, especially in the initial reactions (Ri) in S2 and S4, which increased almost symmetrically. Unexpectedly, the reaction force in $\mathrm{S} 1$ was not altered by the initial deformed vault configuration.

Figure 2-b depicts the initial stiffness values calculated as the slope of the vaults' elastic response (until $5 \mathrm{~mm}$ for the as-built and $10 \mathrm{~mm}$ for the TRM-reinforced vault) of all the monitored supports. The TRM helped re-establish the original stiffness in S1, while S2 and S4 slightly reduced their initial stiffness. A different trend was found in the effectiveness of TRM on the peak forces throughout the tests. A comparison of the response of the as-built and repaired structures is given in Figure 2-c, which shows significantly higher peak reaction forces due to the TRM.

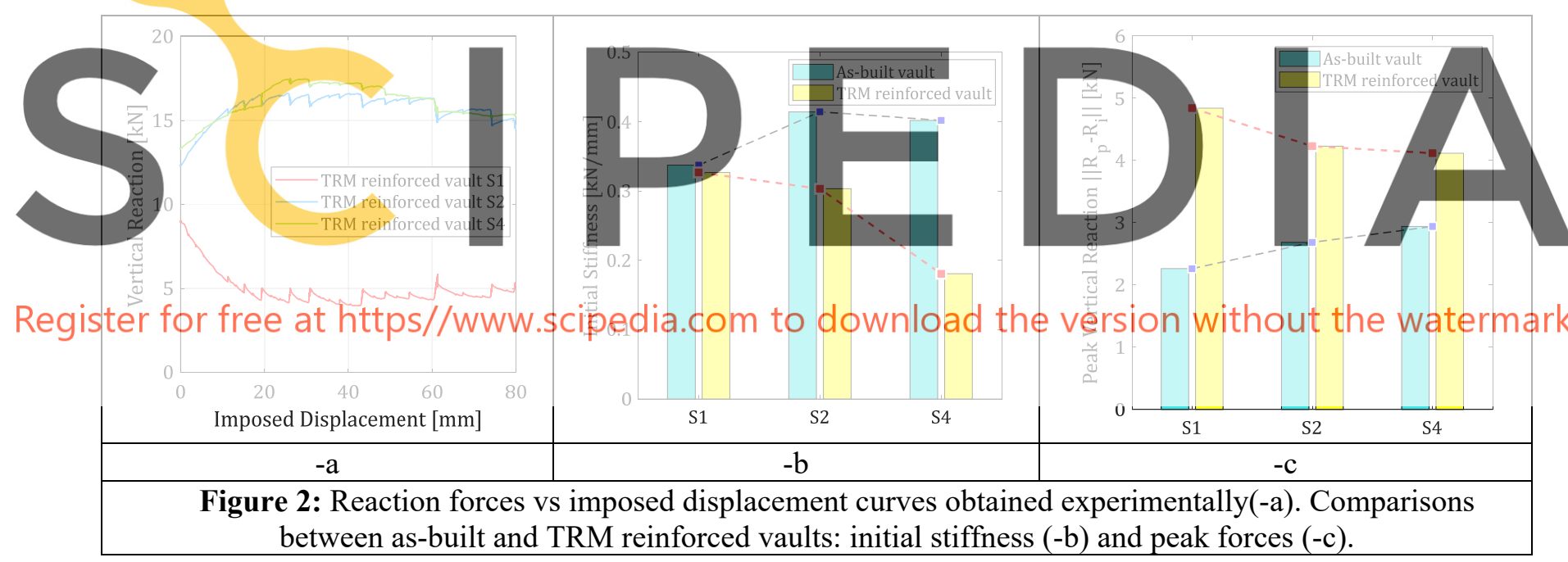

\subsection{Crack Pattern}

At the end of the first test (unreinforced vault subjected to monotonic settlement) [16], the vault experienced: (i) cracks formed on mortar joints on supports S1 and S3 and on some damaged bricks in S2, (ii) a diagonal curved hinge crack opened on the vault extrados and propagated along the diagonal arch towards S2 and S4. As vault stability was seriously threatened, the authors decided to stop the test and carry out repairs. Despite the injections, the TRM-reinforced vault experienced: (i) the opening of one extrados curved hinge connecting supports S2-S4 and (ii) traditional hinge mechanisms in the lateral arches. Hinges were also detected near S2 and S4. The cracks in the extrados opened mostly in the reinforcing mortar (see Figure 3-a). No debonding or fiber-to-matrix slippages were detected 
during the whole series of tests. The activated damage mechanism involved the reinforcing mortar matrix but there was no tensile failure of the glass grid. It should be noted that the cracks on lateral arches S4-S1 and S2-S1 attempted to join up with the diagonal hinge between supports S2-S4. This peculiar failure mechanism also occurred in the unreinforced vault [16] (Figure 3-b). In details, Figure 3-a gives the displacement read by the LVDTs placed on the unreinforced vault (between 0 to $40 \mathrm{~mm}$ ) and the TRM-repaired vault extrados (between 40 to $120 \mathrm{~mm}$ ). LVDT 5 monitored the formation of the hinged diagonal crack along supports S2-S4 on the vault extrados, which doubled in size from $2.5 \mathrm{~mm}$ in the unreinforced to $5 \mathrm{~mm}$ in the reinforced vault.

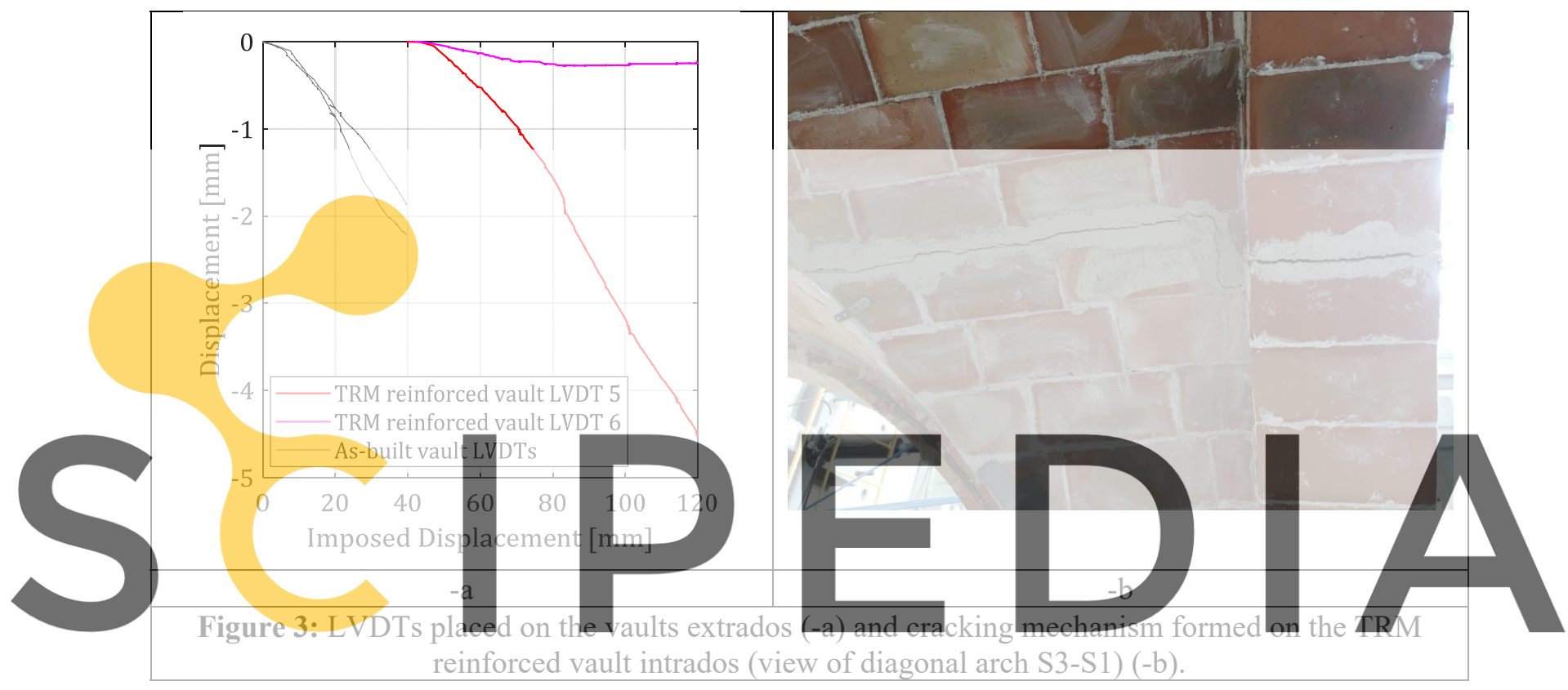

Register for free at https//www.scipedia.com to download the version without the watermark

\section{EXPERIMENTAL RESULTS: CYCLIC SETTLEMENT}

\subsection{Experimental Results}

Figure 4-a depicts the reaction force-displacement curve obtained in support S1 considering the load increments produced only by the displacement protocols. The curve is traced in the same color as the corresponding support number and superimposed on the unreinforced counterpart. The ultimate bearing capacity of the TRM-reinforced vault is significantly greater than that of the as-built structure, as are the corresponding ultimate displacements. Elastic stiffness degradation (Figure 4-b) was computed as the slope of the force-displacement curves monitored in all the cycles of the campaign up to $80 \%$ of the peak reaction forces. As expected, in the TRM-reinforced vault the initial elastic stiffness progressively degraded up to a maximum of four times at $80 \mathrm{~mm}$ in support $\mathrm{S} 1$. The initial stiffness values in the first cycle were quite similar to those of the undamaged unreinforced vault at the beginning of the test. Although negligible differences were detected due to material heterogeneity, the consistency of the values from the beginning of the test confirmed the effectiveness of TRM in recovering the structure's original stiffness. Strength degradation 
is another important parameter (Figure 4-c). Strength degradation curves were drawn using the peak forces obtained in each cycle of all the monitored supports. The as-built and TRMreinforced vaults were normalized with those obtained in the first cycle of the unreinforced vault. As can be seen in Figure 4-c, the TRM strengthening dramatically changed the unreinforced vault's strength degradation trend found in [17]. Unexpectedly, both up and down movements showed a clear increasing trend common to all the supports in all cycles, except for the last cycle of S4. The reduced strength was detected in S4 before the other supports, indicating a faster entry into the energy-consuming state. The TRM-reinforced vault's behavior was quite symmetric under upward and downward settlements.

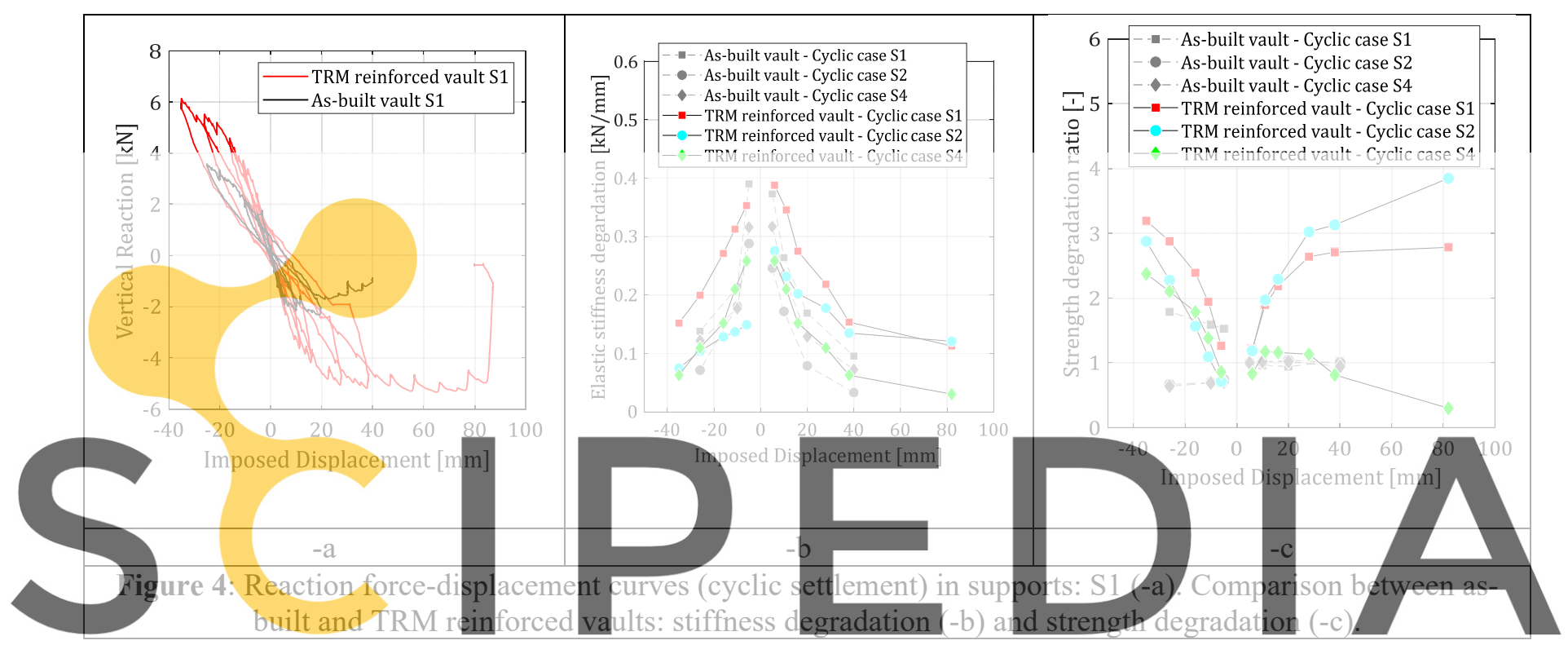
Register for free at https//www.scipedia.com to download the version without the watermark

Similarly to the monotonic case, the TRM-reinforced vault subjected to cyclic settlements experienced the formation of hinges in the lateral arches and the widening of a diagonal crack on arch S2-S4. Figure 5-a depicts the displacements recorded by the LVDTs close to supports S2-S3 and S4 during the testing of the unreinforced and TRM reinforced vaults. The cracks formed during the first test were relatively narrow $(3 \mathrm{~mm})$. In the reinforced vault severe damage was detected on the extrados and intrados of support S2. The base of S2 experienced a deep crack which formed during upward movements. Furthermore, both lateral arches S2-S1 and S2-S3 experienced wide cracks on the extrados which affected the vault's integrity. It is worth mentioning that, those on the former arch opened up to approximately 16 $\mathrm{mm}$. In addition, the TRM experienced preliminary cracking of the reinforcing mortar, followed by the progressive tensile failure of the glass grid. The same failure mechanism was observed in lateral arch S2-S3. In this case, the crack, which propagated across the mortar joints, caused the external layers of masonry to separate. Although a visual inspection showed the crack was similar to the one in arch S2-S1, LVDT 3 could only partially detect it. Only one LVDT tracked the formation of the diagonal hinge that opened between supports S2-S4 on both extrados and intrados due to the cyclic settlement. Thanks to the presence of the TRM 
strengthening, the premature separation of the vault into two independent parts was avoided (Figure 5-b). Figure 5-b shows the crack patterns at the end of the cyclic test in the reinforced vault. The cracks on the extrados were diverted by the reinforcing materials to the masonry away from the retrofitted zones. The TRM radial configuration prevented the crack on the top of the extrados from propagating. The cracks reached a maximum value of $8 \mathrm{~mm}$ at the end of the test in the unreinforced vault, or approximately half the width of the opening in the reinforced vault.

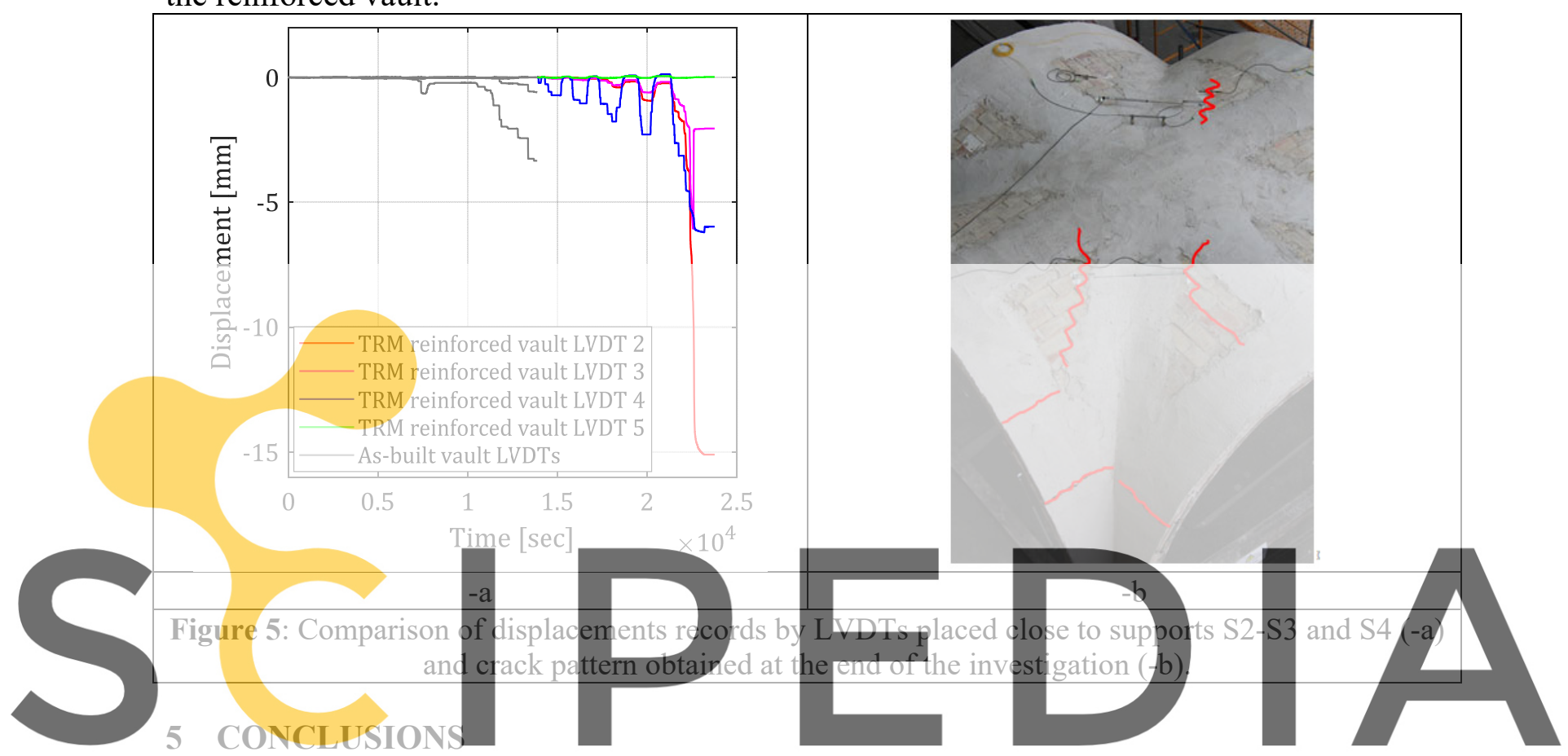

The present work describes a double lab test comprising the application of monotonic and

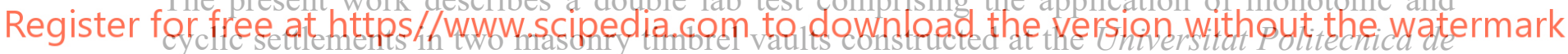

Valencia (Spain). The results obtained allow us to draw the following conclusions:

- The paper describes a repair technique to be used for severely damaged masonry cross vaults composed of: injection, masonry repointing and application of TRM composites in a radial pattern on the extrados.

- TRM composites increased the load-bearing capacity of the masonry cross vaults, almost doubling the peak reaction forces in both cases.

- The proposed radial strengthening configuration almost completely restored the initial elastic stiffness of the damaged vaults in both cases.

- TRM strengthening doubled the vaults' elastic phase and ultimate displacements.

- TRM failure in case of monotonic downward settlement comprised the cracking of the reinforcing mortar. No debonding, fibre-to-matrix slippage or tensile failures of the textile grid were detected.

- TRM failure in case of cyclic vertical movement was characterized by the opening of wide cracks in support S2, with the cracking of the mortar matrix and tensile failure of the glass grid. 


\section{REFERENCES}

[1] Bertolesi E., Adam J.M., Rinaudo P., Calderón P.A. Research and practice on masonry cross vaults - A review, Engineering Structures 180 (2019), pp. 67-88.

[2] D’Altri A.M., Castellazzi G., de Miranda S., Tralli A. Seismic-induced damage in historical masonry vaults: A case-study in the 2012 Emilia earthquake-stricken area. $J$ Build Eng 13 (2017), pp. 224-43. doi:10.1016/j.jobe.2017.08.005.

[3] Atamturktur S., Bornn L., Hemez F. Vibration characteristics of vaulted masonry monuments undergoing differential support settlement. Eng Struct 33 (2011), pp. 247284. doi:10.1016/j.engstruct.2011.04.020.

[4] Acikgoz S., Soga K., Woodhams J. Evaluation of the response of a vaulted masonry structure to differential settlements using point cloud data and limit analyses. Constr Build Mater 150 (2017), pp.916-31. doi:10.1016/j.conbuildmat.2017.05.075.

[5] Carfagnini C., Baraccani S., Silvestri S., Theodossopoulos D. The effects of in-plane shear displacements at the springings of Gothic cross vaults. Constr Build Mater 186 (2018), pp. 219-32. doi:10.1016/j.conbuildmat.2018.07.055.

[6] Alexandros L., Thanasis S.K., Triantafillou C. State-of-the-art on strengthening of masonry structures with textile reinforced mortar (TRM), Constr Build Mater 188 (2018), pp. 1221-1233
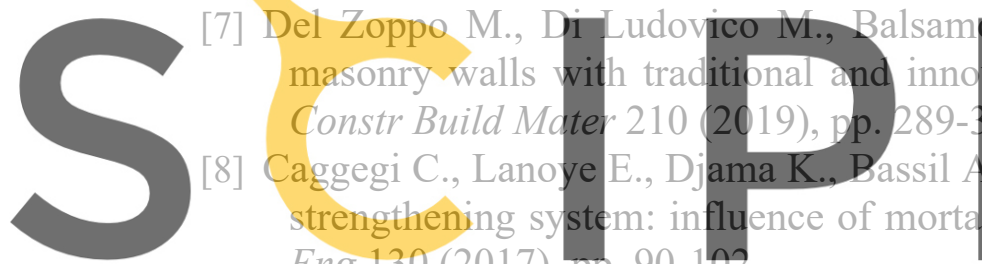
Eng 130 (2017), pp
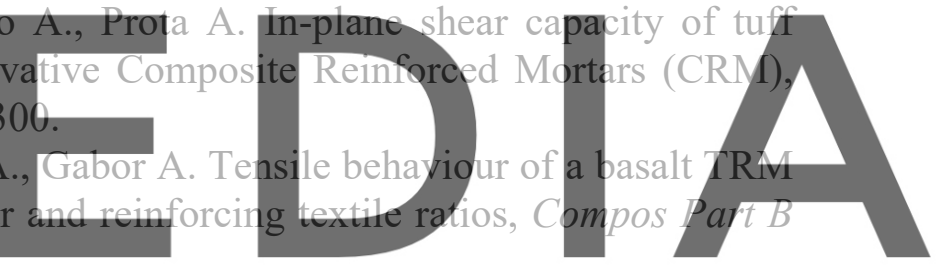

[9] Ascione L., De Felice G., De Santis S. A qualification method for externally bonded Fibre

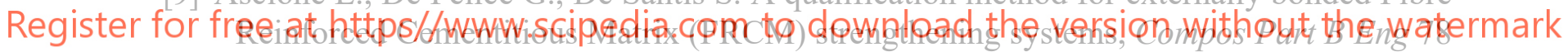
(2015), pp. 497-506.

[10] Wang X., Lam C.C., Paniu V. Companison of different types of TRM composites for strengthening masonry panels, Constr Build Mater 219, (2019), pp. 184-194.

[11] Augenti N., Parisi F., Prota A., Manfredi G. In-plane lateral response of a full-scale masonry sub-assemblage with and without an inorganic matrix-grid strengthening system, J Compos Constr 15 (2011), pp. 578-590.

[12] Kariou F.A., Triantafyllou S.P., Bournas D.A., Koutasc L.N. Out-of-plane response of masonry walls strengthened using textile-mortar system, Constr Build Mater 165 (2018), pp. 769-781.

[13] D'Ambra C., Lignola G.P., Prota A., Sacco E., Fabbrocino F. Experimental performance of FRCM retrofit on out-of-plane behaviour of clay brick walls, Composites Part B 148 (2018), pp. 198-206.

[14] Giamundo V., Lignola G.P., Maddaloni G., Balsamo A., Prota A., Manfredi G. Experimental investigation of the seismic performances of IMG reinforcement on curved masonry elements, Composites: Part B 70 (2015), pp. 53-63. 
[15] Maddaloni G., Di Ludovico M., Balsamo A., Maddaloni G., Prota A. Dynamic assessment of innovative retrofit techniques for masonry buildings, Composites Part B: Engineering 147 (2018), pp. 147-161.

[16] Torres B., Bertolesi E., Moragues J.J., Calderón P.A., Adam J.M. Experimental investigation of a full-scale timbrel masonry cross vault subjected to vertical settlement, Constr Build Mater 221 (2019), pp. 421-432.

[17] Torres B., Bertolesi E., Calderón P.A., Moragues J.J., Adam J.M. A full-scale timbrel cross vault subjected to vertical cyclical displacements in one of its supports, Engineering Structures 183 (2019), pp. 791-804.
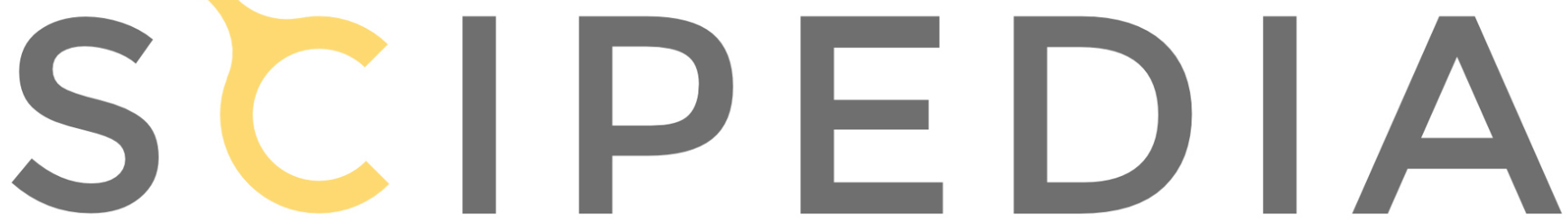

Register for free at https//www.scipedia.com to download the version without the watermark 